\title{
University Students' Perceptions of the Effects of Teacher Self-Disclosure in the English Language Classroom
}

\author{
Mohsine Jebbour \\ Faculty of Arts and Human Sciences Dhar El Mahraz - Fez \\ Sidi Mohamed Ben Abdellah University, Morocco \\ email:mohsine.jebbour@usmba.ac.ma
}

\begin{abstract}
The purpose of this study was to elicit university students' views about the potential effects that teacher self-disclosure may have on classroom outcomes in the university English language environment. Teacher self-disclosure, defined as the use of personal information to explain the course content to students in the classroom, was implemented in the 'spoken English' course in three sessions. The research method for data collection was interviewing 15 first year students attending the course. Thematic analysis was employed to develop common themes from the participants' answers. Results suggest that teacher self-disclosure might be used as an effective instructional practice to increase student motivation, develop a positive teacher-student relationship, enhance cognitive learning, and seek students' attention in the learning process.
\end{abstract}

Keywords: teacher self-disclosure, student motivation, teacher-student relationship, cognitive learning, attention seeking 


\section{INTRODUCTION}

Several empirical studies highlight positive effects of teacher self-disclosure on classroom outcomes. Teacher self-disclosure, defined as the act of sharing personal information to explain the course content to learners in the classroom, helps promote different aspects of student motivation (Gorham \& Christophal, 1992; Cayanus \& Martin, 2008), including affect for teacher and course (Sorensen, 1989), the development of positive attitudes toward English language learning, and the creation of a relaxing climate in the classroom (Farani \& Fatemi, 2014). Teacher self-disclosure also helps increase understanding of the course material (Wambash \& Brothen, 1997; Cayanus \& Martin, 2008), foster different aspects of student participation inside and outside the classroom (Fusani, 1994; Cayanus, Martin, \& Weber, 2003; Cayanus \& Martin, 2004; Cayanus \& Martin, 2008; Cayanus, Martin, \& Myers, 2008; Cayanus, Martin, \& Goodboy, 2009), and develop speaking skills in the English language (Pishghadam and Torghabeh, 2009).

However, focus in most of these studies was on eliciting students' perceptions of their teacher self-disclosure and the outcome variables, instead of eliciting students' opinions about its potential effects when used in classroom teaching. Interestingly, the majority of these studies took place in communication courses at American universities, and very limited research has been conducted in the language classroom. Implementing quantitative methods in previous studies justifies the need for using a qualitative approach in data collection and analysis in this current research to address this methodological gap in the literature. Hence, this study, besides contributing to current research available in the language classroom, implements relevant teacher self-disclosure in the university English language environment in an effort to explore its potential effects on classroom outcomes in the target context.

This study will benefit teachers who are interested in enhancing different aspects of student learning in the college classroom. The urgent demand for tailoring instruction to meet students' immediate needs requires the development of new instructional techniques. Accordingly, the implications derived from this research might help instructors of different subject matters employ self-disclosure to achieve different learning objectives. Results from this study may further encourage researchers to examine new areas of research in the educational context in general and the language classroom in particular.

\section{LITERATURE REVIEW}

Self-disclosure was first a subject of research in interpersonal relationships in psychology and then in communication studies. In psychology, Jourard described self-disclosure as "the act of revealing personal information to others" (Jourard, 1971, p.2), maintaining that sharing personal information with people is an underlying criterion of a healthy personality. In communication studies, Wheeless and Grotz (1976) conceptualized self-disclosure as "any message about the self that a person communicates to another" (p.338). Both definitions suggest that that selfdisclosure was conceptualized generically in that authors did not name the aspects (e.g., cognitive/affective/actions) of the self that people should share with others. 
Given that self-disclosure by teachers has been a subject of research in the teaching-learning context since the 1970s, new operational definitions of the concept have emerged. For example, Sorensen (1989) referred to teacher self-disclosure as "teacher statements in the classroom about the self that may or may not be related to subject content but reveal information about the teacher that students are unlikely to learn from other sources" (p. 260). Goldstein and Benassi (1994) added the dimension of profession in that they defined teacher self-disclosure as "a teacher's sharing of personal and professional information about himself or herself in a believable away" (p.212).

Several dimensions of self-disclosure have been studied in the traditional classroom. These include amount, duration, depth, positivity, negativity, relevance, and appropriateness. Amount pertains to the number of personal issues shared during interaction like using five disclosures in one course; duration corresponds to the time spent in self-disclosure. Conversely, depth is concerned with the intimacy of one's personal information (West \& Turner, 2010), which was found to be socially undesirable with both classmates and teachers (Myers, 1998). Further, positivity entails disclosing 'good' aspects of one's life like getting an 'A' at university. Negativity pertains to 'bad' aspects of one's experience in the classroom, such as drug addiction. Relevance involves sharing disclosures related to the course content (Cayanus et al., 2009). For instance, an instructor can share an experience of collecting data when he/she was a student while teaching research methodology. Appropriateness is concerned with whether the personal information shared by a teacher is socially acceptable in the classroom. Zhang (2009) reported that personal experiences, family, relatives, friends, interests, hobbies, and likes/dislikes were found to be appropriate topics in the classroom context. On the contrary, Cayanus \& Heisler (2013) discovered that students regarded self-disclosures about sex, religion, and politics as inappropriate in class.

Although a number of definitions include several dimensions of teacher selfdisclosure, the operational definition used for inclusion in this study is teacher selfdisclosure, which involves a verbal communication of personal information while explaining the course content (relevance) to students in the classroom. There are two major reasons for putting emphasis on the function of personal information when it is relevant to the course material. First, past research has recommended that teacher self-disclosure which irrelevant to the course material is considered an inappropriate behavior (Cayanus \& Heisle, 2013). Lannutti and Strauman (2006)

confirmed this conclusion, maintaining that

self-disclosures designed to help in explanations of course content

are more likely to be perceived to be intentional by students than instructor self-disclosures that are not related to course material and may therefore appear out-of-place or inappropriate for the classroom setting (p. 96).

Second, different studies suggested that teacher self-disclosure be used to clarify the course materials presented for students (Wambach \& Brothen, 1997; Cayanus \& Martin, 2008). 


\section{RESEARCH METHOD}

\subsection{Research Problem}

This study aimed to find out the potential effects that teacher self-disclosure may have on classroom outcomes in the university English language context in Morocco. To address this issue, the following research question was forwarded:

RQ1: what are the potential effects of teacher self-disclosure on classroom outcomes in the English language context?

\subsection{Setting}

This study was limited to the Fez Dhar EL Mahraz department of English at Sidi Mohamed Ben Abdellah University in Morocco. The teacher (the researcher himself) planned to incorporate personal information to explain the course content in the 'spoken English' course during the autumn semester, which lasted 11 weeks. Part of the course breakdown was discussing the following issues: community service, working women, and traveling. Teacher self-disclosure was present three times in the course throughout the semester. The following examples of teacher selfdisclosure were used:

- When I was in the U.S.A., I used to go with some international students to a Nursing house every week to play games with senior residents. It was an amazing experience. I felt good to draw a smile on the seniors' faces while playing games and chatting.

- In my opinion, husbands whose wives work need to help in house chores because even the religion of Islam does not oblige women to do housework.

- I met people from different Arab countries, such as Lebanon and Egypt at an orientation session in Istanbul, but they could not understand my dialect. So, I switched to English to communicate with them.

\subsection{Participants}

Participants were first-year students enrolled in Fez Dhar El Mahraz department of English studies at Sidi Mohamed Ben Abdellah University during the academic year 2016-2017. After being agreed to participate voluntarily in this study, 15 students (6 males and 9 females) attending the 'spoken English' course once a week for two hours were interviewed at the end of the semester.

\subsection{Instrument}

This study employed a semi-structured interview (see Appendix A) to collect qualitative data from the participants to obtain deep insights into what they thought about the potential effects of relevant teacher self-disclosure on classroom outcomes. This semi-structured interview included the following three questions:

1. How do you feel when teachers use personal disclosures to explain the course content?

2. What do you think of teachers who use personal disclosures to explain the course content? 
3. In what way do teachers who use personal disclosures to explain the course content affect you?

To collect authentic information, the participants were given an example of teacher self-disclosure occurred in the three sessions. All the interviewees were present and ensured perception of the examples of the self-disclosures in class. Four interviews were conducted. 12 out of 15 participants agreed to have their answers audio-recorded, using my phone. In this regard, each interview lasted ten minutes maximum. Alternatively, 3 out of 15 participants preferred to record their answers in written worksheets during the interview.

Anonymity was ensured for all the participants who expressed their willingness to support this research. They were also free to refuse to answer certain items in the interview or decide to withdraw at any stage of the research without the risk of any harms or consequences. For ensuring confidentiality, participants' names were not mentioned when reporting results.

\subsection{Data Analysis}

To examine the potential effects that teacher self-disclosure may have on classroom outcomes in the English language context, thematic analysis was employed to analyze the data collected through the interviews. Initially, the data were transcribed manually. Then, preliminary codes were assigned to the participants' responses to the interview questions. After multiple coding of the data, it was helpful to develop four themes, which were supported by the participants' verbatim examples.

\section{RESULTS}

The participants' answers to the interview questions indicated that relevant teacher self-disclosure might serve as an instructional practice to enhance the following classroom outcomes: student motivation, teacher-student relationship, cognitive learning, and attention seeking.

Table 1: The Participants' Perceptions of the Effects of Teacher SelfDisclosure

\begin{tabular}{|l|l|}
\hline Student motivation & $\begin{array}{l}\text { Positive attitudes toward teacher: the respondents believed } \\
\text { that students develop favorable attitudes toward teachers } \\
\text { who use self-disclosure relevant to the course content. }\end{array}$ \\
\cline { 2 - 2 } & $\begin{array}{l}\text { Intrinsic motivation: according to the interviewees, } \\
\text { students feel interested in the course content when their } \\
\text { teachers use relevant self-disclosure in class. }\end{array}$ \\
\hline $\begin{array}{l}\text { Teacher-student } \\
\text { relationship }\end{array}$ & $\begin{array}{l}\text { For the respondents, relevant teacher self-disclosure helps } \\
\text { establish a good teacher-students relationship. }\end{array}$ \\
\hline Cognitive learning & $\begin{array}{l}\text { According to the respondents, teacher self-disclosure } \\
\text { relevant to the course content is considered a rich source of } \\
\text { information and a tool to clarify the class material. }\end{array}$ \\
\hline
\end{tabular}




\begin{tabular}{|l|l|}
\hline Attention seeking & $\begin{array}{l}\text { The interviewees thought that teacher self-disclosure } \\
\text { relevant to the course content helps attract students' } \\
\text { attention in class. }\end{array}$ \\
\hline
\end{tabular}

\subsection{Student Motivation}

Five out of 15 participants' answers posited that relevant teacher selfdisclosure helps develop two types of student motivation, namely positive attitudes toward teachers and intrinsic motivation. As for attitudes toward teachers, one student pointed out that "teachers that share their personal opinions and feelings in class discussion make me attend every session". Another participant considered teachers who use personal disclosures in class approachable, stating: "personally, I feel comfortable with teachers who share their opinions and experiences because it is a great opportunity to get to know them more, learn from their disclosures, and take them as a good example". The assumption is that when teachers use their selfdisclosures in class, they become accessible to their students, who may feel comfortable to take the initiative to engage in a friendly interaction with their instructors. This suggests that students might develop favorable attitudes toward teachers using relevant self-disclosure.

With respect to intrinsic motivation, 3 participants' answers were as follows: 1) "when teachers share their disclosure, they become approachable, and [their disclosure] increases my level of curiosity about the course"; 2) "when I know more about my teachers' feelings and experiences, I become so excited about the course content", 3) "courses with teachers who use their feelings, opinions, and experiences will be enjoyable". This suggests that teachers' sharing of relevant self-disclosure helps increase feelings of intrinsic motivation in that the students feel interested in and excited about the course content. This might also encourage the students to attend classes regularly and invest more effort in class to master the course content.

\subsection{Teacher-Student Relationship}

Three out of 15 participants' responses indicated that the teachers' communication of self-disclosures to explain the course content helps build a good teacher-student relationship. In this regard, an interviewee conveyed that "teachers who share feelings, opinions, and experiences during class discussion tend to be kind and modest, which will improve a positive relationship with their students". This quote does not only indicate that relevant teacher self-disclosure is tied to desirable characteristics of personality, such as modesty, but shows how teacher self-disclosure affects the teacher-student relationship that is created by those disclosures in class. It becomes evident that professors who use self-disclosure become humane, and the students felt like they could relate to them. This, in turn, may encourage the students to exert more time and effort in the learning operation to enhance their positive relationship with their instructors.

\subsection{Cognitive Learning}

Five out of 15 participants believed that teacher self-disclosure relevant to the course content is related to cognitive learning. On the one hand, two interviewees 
considered teacher self-disclosure a rich source of information. One of them said: "I think teachers' sharing of self-disclosure is good because students learn more information in the classroom". The other one maintained "when my teachers share one of their personal experiences, we learn from it because we may fall in the same situation one day". Thus, rather than learning factual knowledge from the course material, relevant teacher self-disclosure may be used to contribute to student learning.

On the other hand, three participants considered teacher self-disclosure a tool to clarify the class content effectively. Their responses ran as follows: 1) "teachers' personal opinions or experiences during class discussions make me understand the course content easily and even remember every single part of it"; 2) "I do love attending classes where teachers self-disclose their feelings and opinions because sharing helps me understand the course content easily"; 3) "teachers who share personal opinions or experiences make the course content more visible and tangible for us". This reveals that teachers' implementation of self-disclosures is an efficient way for ensuring retention of information and making the course content clearer for the learners.

\subsection{Attention Seeking}

Two out of 15 participants suggested that the teachers' use of relevant personal disclosures helps attract students' attention in class. In this respect, an interviewee argued that "I think that teacher self-disclosure is really effective in keeping students hooked to class discussions and attracting their attention". This indicates that relevant teacher self-disclosure could help the learners concentrate during class discussion, thereby improving their listening skills.

\section{DISCUSSION}

Although past research did not support a positive relation between the amount of teacher self-disclosure and students' affect for instructors in communication courses (Cayanus \& Martin, 2008), results from this study suggested that students are likely to develop positive attitudes toward teachers who use relevant selfdisclosures in the language classroom. Also, teachers' use of relevant disclosures may help increase student interest in the course content. That is, when instructors give a personal example to illustrate a point, students might better interpret the value of the information discussed (Cayanus \& Martin, 2004). In short, this study supports Dörnyei and Csizér's (1998) recommendation that motivating learners in the language classroom requires teachers to 'set a personal example with [their] own behavior' and 'try to fill the tasks with personal content that is relevant to the students'.

The participants also considered relevant teacher self-disclosure an effective means for building a humanistic teacher-student relationship. A number of authors, such as Altman and Taylor (1973) have already argued that disclosing personal information about oneself leads to the development of close relationships. Cayanus and Martin (2004) also revealed that instructor self-disclosure is related to the relational motive. The authors concluded that when teachers self-disclose 
information about themselves, students learn more about their instructors as people. It is no surprise, then, to conclude that self-disclosure is positively associated with overall relationship satisfaction not only in interpersonal relationships (Meeks, Hendrick, \& Hendrick, 1998), but also in the educational context. Accordingly, establishing a positive teacher-student relationship is a salient characteristic of effective teaching, particularly in the language context because it is very likely to encourage teacher-student interaction in the target language.

Additionally, the results posited that relevant teacher self-disclosure is a rich source of information. That is, it helps improve student learning since participants might learn from their instructors' disclosures as Jourard (1971) said: "I can experience your experience most directly if you disclose it to me" (p.78). Fusani (1994) also suggested that "self-disclosure is a rich personal source of studentfaculty communication" (p.249). Accordingly, positive lessons can be drawn from the teachers' personal disclosures, which, for the participants, help offer a better understanding of the class material. This provides additional support for studies which indicated that relevant teacher self-disclosure is an effective instructional technique in increasing the clarity of the course content presented for students (Wambach \& Brothen, 1997; Cayanus \& Martin, 2008). This might encourage learners to exert more effort to master the course material because, as Martin, Chesebro, Weber, and Cole (2001) reported, students feel interested in the subject when teachers provide clearer information in class. Last but not least, the findings indicated that relevant teacher self-disclosure has positive effects on students' performance in terms of attention seeking in the learning context.

This study stresses that university instructors need implement teacher self-selfdisclosure as an effective instructional practice in any subject matter (Cayanus, 2004) to create a beneficial and fruitful learning experience conducive to learning. For instance, communication courses, such as 'public speaking' and 'oral communication' usually aim at developing students' communication skills, such as delivering a presentation. Therefore, a teacher can share his/her personal experience and feelings about the first talk he/she gave when he/she was a student.

Based on the interview's results, teacher self-disclosure might yield a number of positive outcomes in the teaching-learning operation when it is relevant to the course content. First, students' low motivation can be explained by the lack of selfconfidence, especially for freshmen who might quit learning if they experience much anxiety and pressure in the beginning of their academic journey. Teachers, then, need to incorporate disclosures to explain the course content to help reduce anxiety on the part of the learners, who are likely to develop an appreciation for their teachers, attend classes, feel excited about the course material, and exert effort to excel in the subject matter.

Second, in Moroccan higher education, classes are characterized by a kind of formal and depersonalized relationship between teachers and students. Students consider their teachers an authority, especially that the culture of the educational system reinforces hierarchical relationships between professors and students inside and outside class. Accordingly, the relevance of teachers' disclosures helps 
humanize the learning environment in which students are very likely to feel relaxed and encouraged to establish a healthy relationship with their teachers.

Third, it is often challenging for teachers to make learners, low-achievers in particular, to concentrate while introducing the course content, which is necessary for moving to the next grade, especially in Morocco where the culture of reading further references is rare. According to Smith (1979), individuals no longer pay attention to familiar stimuli. Given that teacher disclosure supplements new information in class, it could be used to capture students' attention and makes the course material clearer for them.

Like any piece of research, this study had three limitations. First, this study did not consider other dimensions of teacher self-disclosure. Likewise, second and third year students were not involved in this study. If participated, this study could have offered a comprehensive discussion of the effects of teacher self-disclosure in the language classroom. The reason for not including second and third year students was due to the fact that the researcher had the opportunity to teach only first year students. Finally, the participants could have tried to provide answers that impress the researcher (their teacher) instead of expressing themselves frankly. If another researcher interviewed the students, different themes could have emerged from the data.

Thus, a number of implications for future research should be considered. To have a clearer understanding of teacher self-disclosure in classroom teaching, other dimensions of teacher self-disclosure, such as positivity and appropriateness need to be measured in future studies. Additionally, researchers need to examine the relationship between teacher self-disclosure and each of the identifying classroom outcomes (e.g., student motivation, teacher-student relationship) derived from this study. Lastly, exploring the effects of teacher self-disclosure in other language classes, like French and undergraduate levels would help show whether the themes generated from this study are similar or different to other subject matters and levels.

\section{CONCLUSION}

Teacher self-disclosure, including feelings, opinions, and experiences might be an effective instructional practice to increase student motivation, develop a positive teacher-student relationship, enhance cognitive learning, and draw students' attention in the classroom. Yet, the effectiveness of teacher self-disclosure lies in its relevance since it should be more illustrative than revealing (Lannutti \& Strauman, 2006).

\section{REFERENCES}

Altman, I., \& Taylor, D. (1973). Social penetration: The development of interpersonal relationships. New York: Holt, Rinehart \& Winston.

Cayanus, J. L. (2004). Using teacher self-disclosure as an instructional tool. Communication Teacher, 18(1), 6-9.

Cayanus, J. L., \& Heisler, J. (2013). Teacher self-disclosure: Exploring a fourth dimension. Paper presented at the annual meeting of the National Communication Association, Washington, DC. 
Cayanus, J. L., \& Martin, M. M. (2004). An instructor self-disclosure scale. Communication Research Reports, 21(3), 252-263.

Cayanus, J. L., \& Martin, M. M. (2008).Teacher self-disclosure: Amount, relevance and negativity. Communication Quarterly, 56(3), 325-341.

Cayanus, J. L., Martin, M. M., \& Goodboy, A. K. (2009). The relationship between teacher self-disclosure and student motives to communicate. Communication Research Reports, 26(2), 105-113.

Cayanus, J. L., Martin, M. M., \& Myers, S. A. (2008). The relationship between perceived instructor self-disclosure and college student information seeking. Texas Speech Communication Journal, 33(1), 20-26.

Cayanus, J. L., Martin, M. M., \& Weber, K.D. (2003). The relationships between teacher self-disclosure and out-of-class communication, student interest, and cognitive learning. Paper presented at the annual meeting of the Southern States Communication Association, AL.

Cayanus, J. L., \& Martin, M. M. (2016). Teacher self-disclosure. In P.L. Witt (Ed.), Handbook of communication science: Vol: 16. Communication and Learning pp.241-258). Berlin: DeGruyter Mouton.

Dörnyei, Z., \& Csizér, K. (1998). Ten commandments for motivating language learners: Results of an empirical study. Language Teaching Research, 2(3), 203-229.

Downs, V. C., Javidi, M., \& Nussbaum, J. F. (1988). An analysis of teacher's verbal communication within the college classroom: Use of humor, self-disclosure, and narratives. Communication Education, 37(2), 127-141.

Farani, S. T., \& Fatemi, A. H. (2014). The impact of teacher's self-disclosure on students' attitude towards language learning in a foreign language context. Theory and Practice in Language Studies, 4, 2415-2422. doi:10.4304/tpls.4.11.2415-2422

Fusani, D. S. (1994). "Extra-class" communication: Frequency, immediacy, selfdisclosure, and satisfaction in student-faculty interaction outside the classroom. Journal of Applied Communication Research, 22(3), 232-255.

Goldstein, G. S., \& Benassi, V. A. (1994). The relation between teacher selfdisclosure and student classroom participation. Teaching of Psychology, 21(4), 212-217.

Gorham, J. \& Christophel, D. M. (1990). The relationship of teachers' use of humor in the classroom to immediacy and student learning. Communication Education, 39(1), 46-62.

Jourard, S. (1971). The transparent self. Princeton, NJ: Van Nostrand.

Lannutti, P. J., \& Strauman, E. C. (2006, February). Classroom communication: The influence of instructor self-disclosure on student evaluations. Communication Quarterly 54(1), 89-99.

Martin, M. M., Chesebro, J. L., Weber, K. D., \& Cole, J. G. (2001, May). The importance of being clear on the first day of class: Instructor clarity, credibility, and student interest. Paper presented at the International Communication Association Convention, Washington, DC. 
Meeks, B.S., Hendrick, S.S., \& Hendrick, C. (1998). Communication, love and relationship satisfaction. Journal of Social and Personal Relationships, 15(6), 755-773.

Nussbaum, J. F., Comadena, M. E., \& Holladay, S. J. (1987). Classroom verbal behavior of highly effective teachers. Journal of Thought, 22(4), 73-80.

Pishghadam, R., \& Torghabeh, R.A. (2009). The impacts of teacher self-disclosure on the speaking ability of EFL learners. In P. Roberston \& R.A. Torghabeh (Eds.), The Iranian EFL Journal Quarterly, 3(11), 36-47.

Sorensen, G. (1989). The relationships among teachers' self-disclosure, students' perceptions, and affective learning. Communication Education, 38(3), 259276.

Smith, N.M. (1979). Allocation of time and achievement in elementary social studies. Journal of Educational Research, 72(4), 231-236.

Wambach, C., \& Brothen, T. (1997). Teacher self-disclosure and student classroom participation revisited. Teaching of Psychology, 24(4), 262-263.

Wheeless, L. R., \& Grotz, J. (1976). Conceptualization and measurement of reported self- disclosure. Human Communication Research, 2(4), 338-346.

Zhang, Sh, Shi, Q., Tonelson, T. \& Robinson, R. (2009). Preservice and inservice teachers' perception of the appropriateness of teacher self-disclosure. Teaching and Teacher Education, 25(8), 117-1124.

\section{Appendix A: Semi-structured Interview Questions}

The purpose of this interview is to elicit students' views of teacher selfdisclosure in the 'spoken English' course. In this study, self-disclosure refers to teachers' verbal communication of personal information to explain the course content to students in the classroom.

To make it clearer, if you can remember in one of the 'spoken English' sessions, we discussed the importance of community service in student life, and I used my personal experience to explain what community service is. I said: when I was in the U.S.A., I used to go to a nursing house every week to play games with senior residents, which is your teacher's personal experience.

Now that you know what relevant teacher self-disclosure means, I would like you to answer the following questions. I am interested in your personal views of the use of teacher self-disclosure in class. Your answers will be used for research purposes only. Thank you for your help in advance.

1. How do you feel when teachers use personal disclosures to explain the course content?

2. What do you think of teachers who use personal disclosures to explain the course content?

3. In what way do teachers who use personal disclosures to explain the course content affect you? 